\title{
Thermal Polycondensations of Alkali Bromomethylbenzoates or Alkali (4-Bromomethylphenyl)acetates in the Solid State
}

\author{
Mari InOKI, Fumihiko Akutsu, ${ }^{\dagger}$ Yasuyuki Kitayama, \\ Yoshio Kasashima, and Kiyoshi NarUCHI \\ Department of Applied Chemistry, Faculty of Engineering, Chiba University, \\ Yayoi-cho 1-33, Inage-ku, Chiba 263, Japan
}

(Received May 24, 1996)

KEY WORDS Alkali Salts / 3-Bromomethylbenzoic Acid / 4-Bromomethylbenzoic Acid / (4Bromomethylphenyl)acetic Acid / Solid State / Polycondensation / Polyester /

We previously reported the thermal reactions of alkali and alkaline earth 2-bromobutyrates in the solid state to cause polycondensation without elimination of hydrogen bromide. ${ }^{1}$ The polyester, whose number-average molecular weight is $c a$. 4000 , was obtained from the sodium $(\mathrm{Na})$ and potassium $(\mathrm{K})$ salts. From lithium (Li) and alkaline earth salts, oligoesters including dimers and trimers were given. The thermal reactions of alkali and alkaline earth 2-halogenopropanoates in the solid state were also studied, and the brominated salt indicated higher reactivity than the corresponding chlorinated salt. ${ }^{2}$ However, the solid-state thermal reactions of salts of halogenated aromatic carboxylic acids have not been studied.

In the present study, thermal reactions of alkali salts of bromomethylbenzoic acids (BMBA) or those of (4bromomethylphenyl)acetic acid (BMPAA) in the solid state were investigated. Cameron et al. reported the interfacial polycondensation of Na-4-BMBA using 18-crown-6 as a phase transfer catalyst to obtain an oligoester. ${ }^{3}$ Pinkus et al. reported the solution polycondensations of 3- and 4-BMBA using triethylamine as a hydrogen-bromide acceptor, producing poly(oxycarbonyl-1,3-phenylenemethylene) $\mathbf{1}$ and poly(oxycarbonyl-1,4-phenylenemethylene) 2 , respectively. ${ }^{4}$ The values of the inherent viscosity of the polyesters, given by polycondensation, were low (below $0.19 \mathrm{dLg}^{-1}$ ) due to the low solubility of the polyesters, which are soluble at room temperature in a mixed solvent of 1,1,2,2-tetrachloroethane (TCE) with phenol (ratio of TCE/phenol, $40 / 60$ by weight $^{5,6}$ or $o$-chlorophenol ${ }^{7}$ alone. However, in the solid-state reaction, polycondensation is not affected by the solubility of the polymer in solvents. Polyester 1 was synthesized by the direct polycondensation of 4-hydroxymethylbenzoic acid ${ }^{5,8-10}$ and transesterification. . $^{5,810-14}$ Polyester 2 was synthesized by the direct polycondensation of 3-hydroxymethylbenzoic acid $^{5,8}$ and transesterification. ${ }^{11,13,14}$ Poly(oxycarbonylmethylene-1,4-phenylenemethylene) (polyester 3) has not been reported.

\footnotetext{
$\uparrow$ To whom correspondence should be addressed.
}

\section{EXPERIMENTAL}

\section{Preparation of Monomeric Salts}

2-, 3-, and 4-Methylbenzoic acids were obtained from Tokyo Kasei Kogyo Co., Ltd. The brominated carboxylic acids were prepared by the bromination of the corresponding methylbenzoic acid using $N$-bromosuccinimide with a slight amount of benzoyl peroxide in tetrachloromethane according to the method reported previously. ${ }^{15-17}$ All products were recrystallized from ethyl acetate. mp, 2-BMBA, $146.1-148.2^{\circ} \mathrm{C}$ (lit. ${ }^{18,19}$ $146^{\circ} \mathrm{C}$ ); 3-BMBA, $155.8-157.2^{\circ} \mathrm{C}$ (lit. ${ }^{4} 151-153^{\circ} \mathrm{C}$ ); 4-BMBA, 230.9-232.2 ${ }^{\circ} \mathrm{C}$ (lit. ${ }^{4} 227-229^{\circ} \mathrm{C}$ ). 4-BMPAA was obtained from Aldrich Chemicals Co., Inc., and used as received.

The monomeric salts were prepared by neutralizing the brominated carboxylic acids with metal hydroxides in methanol using phenolphthalein as an indicator. After removal of methanol on a rotary evaporator, the residue was washed with ether, and dried under reduced pressure.

Anal.

Li-3-BMBA: Calcd for $\mathrm{C}_{8} \mathrm{H}_{6} \mathrm{O}_{2} \mathrm{BrLi}$ (221.0): C, $43.48 \%$; $\mathrm{H}, 2.74 \%$. Found: $\mathrm{C}, 43.08 \%$; $\mathrm{H}, 2.74 \%$. Na-3-BMBA: Calcd for $\mathrm{C}_{8} \mathrm{H}_{6} \mathrm{O}_{2} \mathrm{BrNa}$ (237.0): C, $40.54 \% ; \mathrm{H}, 2.55 \%$. Found: C, $40.20 \%$; $\mathrm{H}, 2.56 \%$. $(\mathrm{K}-3-\mathrm{BMBA})_{2} \mathrm{H}_{2} 0$ : Calcd for $\mathrm{C}_{16} \mathrm{H}_{14} \mathrm{O}_{5} \mathrm{Br}_{2} \mathrm{~K}_{2}$ (524.3): C, $36.65 \%$; H, $2.69 \%$. Found: C, $36.67 \%$; H, $2.45 \%$. Li-4-BMBA: Calcd for $\mathrm{C}_{8} \mathrm{H}_{6} \mathrm{O}_{2} \mathrm{BrLi}(221.0)$ : C, $43.48 \%$; $\mathrm{H}, 2.74 \%$. Found: $\mathrm{C}, 43.41 \%$; $\mathrm{H}, 2.50 \%$.

Na-4-BMBA: Calcd for $\mathrm{C}_{8} \mathrm{H}_{6} \mathrm{O}_{2} \mathrm{BrNa}$ (237.0): $\mathrm{C}$, $40.54 \%$; H, $2.55 \%$. Found: C, $40.83 \%$; H, $2.41 \%$.

K-4-BMBA: Calcd for $\mathrm{C}_{8} \mathrm{H}_{6} \mathrm{O}_{2} \mathrm{BrK}$ (253.1): C, $37.96 \%$; H, 2.39\%. Found: C, 37.94\%; H, 2.09\%.

Li-4-BMPAA: Calcd for $\mathrm{C}_{9} \mathrm{H}_{8} \mathrm{O}_{2} \mathrm{BrLi}$ (235.0): C, $46.00 \%$; H, 3.43\%. Found: $\mathrm{C}, 46.22 \%$; H, 3.58\%.

$\mathrm{Na}$-4-BMPAA: Calcd for $\mathrm{C}_{9} \mathrm{H}_{8} \mathrm{O}_{2} \mathrm{BrNa}$ (251.0): C, $43.06 \%$; H, 3.21\%. Found: C, $42.71 \%$; H, 3.18\%.

K-4-BMPAA: Calcd for $\mathrm{C}_{9} \mathrm{H}_{8} \mathrm{O}_{2} \mathrm{BrK}$ (267.2): C, $40.46 \%$; H, 3.02\%. Found: C, $40.06 \%$; H, 3.00\%.

2-BMBA was neutralized with metal hydroxides, and a white precipitate was formed. Melting point of the precipitate was $71.4-72.8^{\circ} \mathrm{C}$ (literature melting point of phthalide, $73^{\circ} \mathrm{C}^{19} ; 72-73^{\circ} \mathrm{C}^{20}$ ). Thus, the monomeric salts of 2-BMBA could not be obtained. 


\section{Thermal Reactions}

The monomeric salt $(0.5 \mathrm{~g})$ was put into a Pyrex tube, and heated in an oil bath under reduced pressure. After heating, the reaction mixture was dissolved in the mixed solvent (TCE/phenol, 40/60 by weight), filtrated with a glass filter, and poured into methanol for precipitation. The precipitate was collected by filtration with a glass filter, washed with hot methanol, and dried under reduced pressure. The product was purified by reprecipitation (the mixed solvent/methanol), followed by washing with hot methanol.

Anal.

1: Calcd for $\left(\mathrm{C}_{8} \mathrm{H}_{6} \mathrm{O}_{2}\right)_{n}(134.1)_{n}$ : C, 71.63\%; H, $4.51 \%$. Found: C, 69.15\%; H, 4.28\%. IR (KBr): 1724 $(\mathrm{C}=\mathrm{O}), 1274,1196(\mathrm{C}-\mathrm{O}) \mathrm{cm}^{-1}$.

2: Calcd for $\left(\mathrm{C}_{8} \mathrm{H}_{6} \mathrm{O}_{2}\right)_{n}(134.1)_{n}: \mathrm{C}, 71.63 \% ; \mathrm{H}$, $4.51 \%$. Found: C, 69.65\%; H, $4.38 \%$. IR (KBr): 1720 $(\mathrm{C}=\mathrm{O}), 1268,1178(\mathrm{C}-\mathrm{O}) \mathrm{cm}^{-1}$.

3: Calcd for $\left(\mathrm{C}_{9} \mathrm{H}_{8} \mathrm{O}_{2}\right)_{n}(148.2)_{n}$ : C, 72.96\%; H, $5.44 \%$. Found: C, $71.43 \% ; \mathrm{H}, 5.39 \%$. IR (KBr): 1730 $(\mathrm{C}=\mathrm{O}), 1224,1152(\mathrm{C}-\mathrm{O}) \mathrm{cm}^{-1}$.

\section{Measurements}

IR spectra were recorded on a Hitachi 270-30 spectrophotometer. Wide angle X-ray diffraction patterns were obtained for specimens on Rigaku XG X-ray diffraction apparatus with $\mathrm{Cu}-K_{\alpha}$ radiation $(35 \mathrm{kV}, 20 \mathrm{~mA})$. Inherent viscosity was measured at a concentration of $0.5 \mathrm{~g}$ per $100 \mathrm{~mL}$ in TCE/phenol ( $40 / 60$ by weight). Thermoanalytical measurements by differential scanning calorimetry (DSC; Rigaku DSC 8230D) and thermogravimetry-differential thermal analysis (TG-DTA; Mac science TG-DTA 2000) were carried out under the following conditions: heating rate, $10 \mathrm{~K} \mathrm{~min}^{-1}$; in nitrogen atmosphere.

\section{RESULTS AND DISCUSSION}

\section{Preparation of the Monomeric Salts}

2-BMBA was neutralized in methanol by metal hydroxides to prepare the monomeric salts, and a white precipitate was formed. The precipitate was identified by IR spectroscopy and the melting point as phthalide, ${ }^{18,19}$ which contains a five-membered lactone ring. Chauffe et al. reported that 2-BMBA is converted to phthalide in alkali solution. ${ }^{21}$ Thus, the monomeric salts of 2-BMBA could not be obtained. The monomeric salts of other brominated carboxylic acids, such as 3-BMBA, 4-BMBA, and 4-BMPAA, were prepared and identified by elemental analysis. K-3-BMBA had 1/2 molar water of crystallization.

\section{Thermal Reactions of the Salts}

TG-DTA curves of all $\mathrm{Na}$ and $\mathrm{K}$ salts showed exothermic peaks without decomposition below $250^{\circ} \mathrm{C}$. However, DTA curves of all Li salts did not show exothermic peaks. These results are summarized in Table I. DSC curves of all the salts did not indicate endothermic peaks by melting below the temperature of the exothermic peaks by the heat of reaction. Based on these results, reaction temperatures were determined.

Thermal reactions of the salts of 3-BMBA were carried out at $140-160^{\circ} \mathrm{C}$ for $2-3 \mathrm{~h}$ under reduced pressure.
The reaction mixture was dissolved in mixed solvent of TCE with phenol, filtrated with a glass filter to remove alkali bromides, and poured into methanol for precipitation. After purification, inherent viscosities and IR spectra were measured. The products were identified as polyester 1 by IR spectroscopy as well as elemental analysis. These results indicated that thermal reactions of alkali salts of 3-BMBA in the solid state cause polycondensation, to produce polyester $\mathbf{1}$, as shown in Scheme 1. The results are tabulated in Table II.

From Li-3-BMBA, polyester 1 was obtained in lower

Table I. TG-DTA analysis of salts

\begin{tabular}{|c|c|c|}
\hline \multirow{2}{*}{ Salt } & Exothermic temp & Decomposition temp \\
\hline & ${ }^{\circ} \mathrm{C}$ & ${ }^{\circ} \mathrm{C}$ \\
\hline $\mathrm{Li}-3-\mathrm{BMBA}$ & $-^{a}$ & 265 \\
\hline $\mathrm{Na}-3-\mathrm{BMBA}$ & 168 & 372 \\
\hline K-3-BMBA & 157 & 378 \\
\hline $\mathrm{Li}-4-\mathrm{BMBA}$ & ${ }^{\mathrm{a}}$ & 304 \\
\hline $\mathrm{Na}-4-\mathrm{BMBA}$ & 294 & 388 \\
\hline $\mathrm{K}-4-\mathrm{BMBA}$ & 264 & 390 \\
\hline Li-4-BMPAA & ${ }^{a}$ & 245 \\
\hline $\mathrm{Na}$-4-BMPAA & 164 & 254 \\
\hline K-4-BMPAA & 135 & 301 \\
\hline
\end{tabular}

${ }^{\mathrm{a}}$ Not observed.

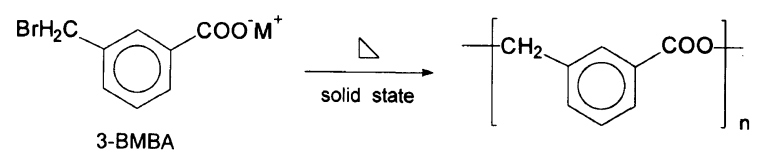

Polyester 1
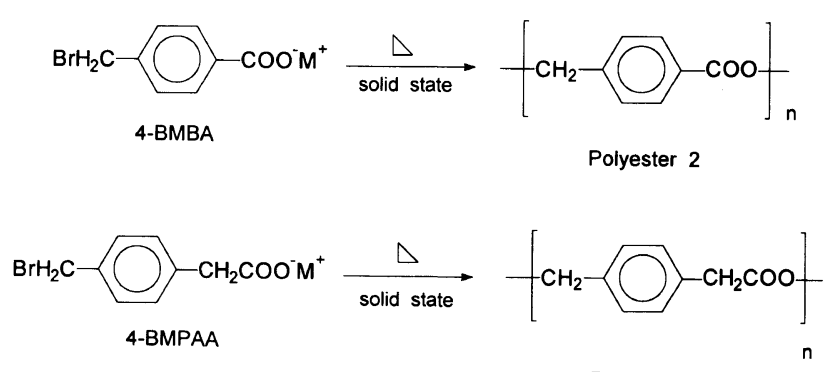

Polyester 3

Scheme 1.

Table II. Solid-state thermal polycondensation of the salts of 3-BMBA

\begin{tabular}{|c|c|c|c|c|}
\hline \multirow{2}{*}{ Salt } & Temp & Time & Yield & $\eta_{\mathrm{inh}}^{\mathrm{a}}$ \\
\hline & ${ }^{\circ} \mathrm{C}$ & $\mathrm{h}$ & $\%$ & $\mathrm{dLg}^{-1}$ \\
\hline $\mathrm{Li}$ & 120 & 2 & 2.3 & $ـ^{b}$ \\
\hline $\mathrm{Li}$ & 140 & 2 & 20.1 & ${ }^{b}$ \\
\hline $\mathrm{Li}$ & 150 & 2 & 13.3 & ${ }^{b}$ \\
\hline $\mathrm{Li}$ & 150 & 3 & 10.5 & b \\
\hline $\mathrm{Na}$ & 140 & 2 & 55.1 & 0.14 \\
\hline $\mathrm{Na}$ & 150 & 2 & 81.9 & 0.21 \\
\hline $\mathrm{Na}$ & 150 & 3 & 82.2 & 0.21 \\
\hline $\mathrm{Na}$ & 160 & 2 & 83.7 & 0.21 \\
\hline $\mathrm{K}$ & 130 & 2 & 88.0 & 0.20 \\
\hline $\mathrm{K}$ & 140 & 2 & 94.0 & 0.29 \\
\hline $\mathrm{K}$ & 140 & 3 & 89.0 & 0.33 \\
\hline $\mathrm{K}$ & 150 & 2 & 88.6 & 0.21 \\
\hline
\end{tabular}

${ }^{\text {a }}$ Inherent viscosity measured in TCE/phenol (40/60 by weight) at $30{ }^{\circ} \mathrm{C}$. ${ }^{b}$ Yield was so low that inherent viscosity could not be measured. 


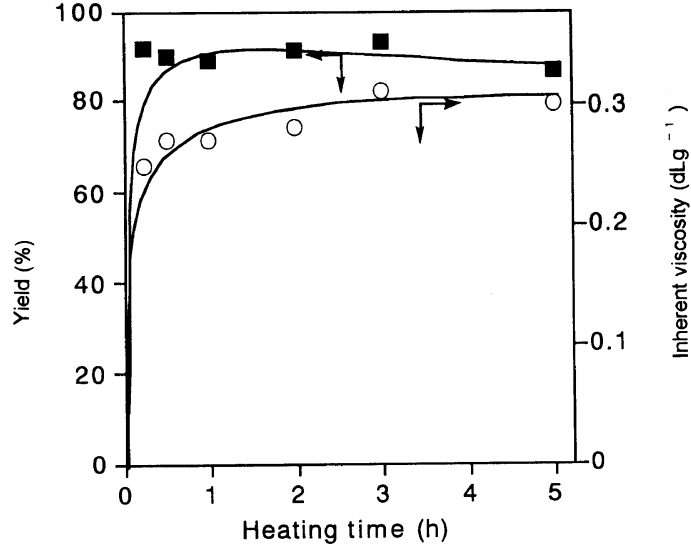

Figure 1. Thermal reactions of $\mathrm{K}-3-\mathrm{BMBA}$ in the solid state at $140^{\circ} \mathrm{C}$.

yield. The thermal reactions of Na-3-BMBA at $150-$ $160^{\circ} \mathrm{C}$ for $2 \mathrm{~h}$ gave polyester 1 in yield above $80 \%$. Inherent viscosity was found to be $0.21 \mathrm{dL} \mathrm{g}^{-1}$. $\mathrm{K}-3$-BMBA indicated the highest reactivity in the alkali salts. The inherent viscosity of polyester 1 , formed by the thermal reaction of $\mathrm{K}-3$-BMBA at $140^{\circ} \mathrm{C}$ for $3 \mathrm{~h}$, $0.33 \mathrm{dL} \mathrm{g}^{-1}$. The yield and inherent viscosity of polyester 1 from $\mathrm{K}-3$-BMBA at $140^{\circ} \mathrm{C}$ are shown as functions of reaction time in Figure 1. After $15 \mathrm{~min}$, the yield was almost quantitative, and inherent viscosity was 0.25 $\mathrm{dLg}^{-1}$. The inherent viscosity increased with time slightly, and, after $3 \mathrm{~h}$, was $0.33 \mathrm{dL} \mathrm{g}^{-1}$. In the solid-state thermal reaction of salts of the brominated aliphatic carboxylic acids, molecular weight increased with time gradually after $4 \mathrm{~h} .{ }^{1,2}$ It was considered that, initially, the reaction was affected by crystallinity and molecular arrangement in the solid state of the monomeric salt, and as the reaction proceeded, the reaction was influenced mainly by the mobility of the molecular chain. The molecular chain of polyester $\mathbf{1}$ is rigider than those of polyesters from the salts of the aliphatic carboxylic acids due to the aromatic ring in the main chain. This may contribute to slight polycondensation of $\mathrm{K}-3$ BMBA after $15 \mathrm{~min}$.

The X-ray diffraction patterns showed that $\mathrm{Li}-$ and Na-3-BMBA form amorphous salts, and K-3-BMBA forms a crystalline salt. In the solid-state polymerization, crystallinity and crystal structures of the monomeric salts largely affect reactivity. ${ }^{22,23}$ In the solid-state thermal reactions of salts of 2-bromobutyric acid and 2-bromopropanoic acid, the reactivity of the salts depended on crystallinity, and the salt having the low crystallinity or amorphous nature indicated the lower reactivity. ${ }^{1,2}$ The relative reactivity of the salts of 3-BMBA decreased in the order: $\mathrm{K}>\mathrm{Na} \gg \mathrm{Li}$. It was considered that the counter cation influences molecular arrangement, which may be favorable to polycondensation. Therefore, the highest reactivity of the $\mathrm{K}$ salt was attributed to high crystallinity and effects of potassium cation on molecular arrangement.

The thermal reactions of the alkali salts of 4-BMBA were performed at $220-240^{\circ} \mathrm{C}$, and those of salts of 4-BMPAA were conducted at $140-160^{\circ} \mathrm{C}$. The reaction mixtures were treated as described above. The products were identified as polyester $\mathbf{2}$ and $\mathbf{3}$ by IR spectroscopy
Table III. Solid-state thermal polycondensation of the salts of 4-BMBA

\begin{tabular}{|c|c|c|c|c|}
\hline \multirow{2}{*}{ Salt } & Temp & Time & Yield & $\eta_{\mathrm{inh}}^{\mathrm{a}}$ \\
\hline & ${ }^{\circ} \mathrm{C}$ & $\mathrm{h}$ & $\%$ & $\mathrm{dL} \mathrm{g}^{-1}$ \\
\hline $\mathrm{Li}$ & 230 & 2 & n.r. ${ }^{b}$ & \\
\hline $\mathrm{Na}$ & 220 & 2 & 61.4 & 0.14 \\
\hline $\mathrm{Na}$ & 220 & 3 & 71.9 & 0.17 \\
\hline $\mathrm{Na}$ & 230 & 2 & 94.8 & 0.21 \\
\hline $\mathrm{Na}$ & 230 & 3 & 98.9 & 0.21 \\
\hline $\mathrm{Na}$ & 240 & 2 & 91.3 & 0.16 \\
\hline K & 220 & 2 & 86.0 & 0.27 \\
\hline $\mathrm{K}$ & 230 & 2 & 97.1 & 0.34 \\
\hline $\mathrm{K}$ & 240 & 2 & 81.0 & 0.28 \\
\hline
\end{tabular}

${ }^{\text {a }}$ Inherent viscosity measured in TCE/phenol ( $40 / 60$ by weight) at $30^{\circ} \mathrm{C}$. ${ }^{\mathrm{b}}$ No reaction.

Table IV. Solid-state thermal polycondensation of the salts of 4-BMPAA

\begin{tabular}{|c|c|c|c|c|}
\hline \multirow{2}{*}{ Salt } & Temp & Time & Yield & $\eta_{\mathrm{inh}}^{\mathrm{a}}$ \\
\hline & ${ }^{\circ} \mathrm{C}$ & $\mathrm{h}$ & $\%$ & $\mathrm{dL} \mathrm{g}^{-1}$ \\
\hline $\mathrm{Li}$ & 230 & 2 & n.r. ${ }^{b}$ & \\
\hline $\mathrm{Na}$ & 140 & 2 & 59.9 & 0.15 \\
\hline $\mathrm{Na}$ & 150 & 2 & 45.8 & 0.11 \\
\hline $\mathrm{Na}$ & 160 & 2 & 85.2 & 0.28 \\
\hline $\mathrm{K}$ & 130 & 2 & 86.8 & 0.11 \\
\hline K & 140 & 2 & 98.4 & 0.17 \\
\hline $\mathrm{K}$ & 150 & 2 & 90.0 & 0.25 \\
\hline $\mathrm{K}$ & 160 & 2 & 92.2 & 0.30 \\
\hline
\end{tabular}

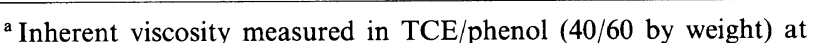
$30^{\circ} \mathrm{C}$. b No reaction.

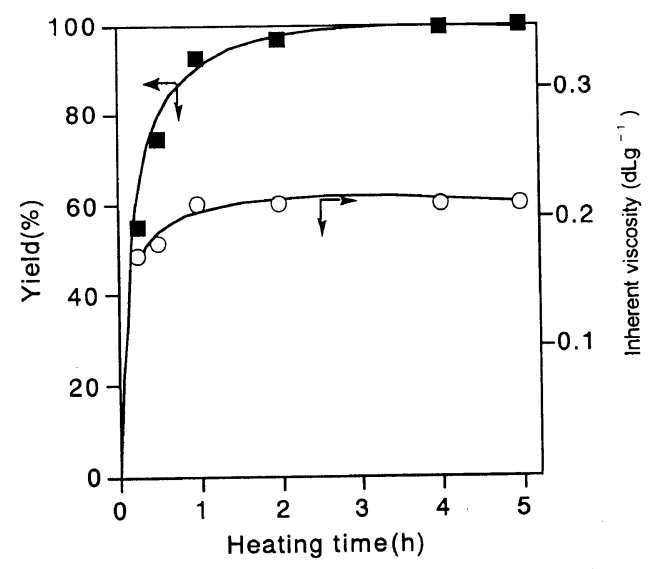

Figure 2. Thermal reactions of $\mathrm{Na}-4-\mathrm{BMBA}$ in the solid state at $230^{\circ} \mathrm{C}$.

as well as elemental analysis, respectively. The results are summarized in Tables II and III, respectively.

The thermal reactions of $\mathrm{Na}-$ and $\mathrm{K}-4$-BMBA almost quantitatively produced polyester 2 . The inherent viscosities ranged from 0.14 to $0.34 \mathrm{dLg}^{-1}$, but needed higher reaction temperature than those of 3-BMBA and 4-BMPAA. The reactions of $\mathrm{Na}-$ and $\mathrm{K}-4$-BMPAA formed polyester 3 , having inherent viscosity from 0.11 to $0.30 \mathrm{dL} \mathrm{g}^{-1}$. The yield and inherent viscosity of polyester 2 in the thermal reaction of $\mathrm{Na}-4-\mathrm{BMBA}$ at $230^{\circ} \mathrm{C}$ are shown as functions of reaction time in Figure 2. The yield was almost quantitative after $1 \mathrm{~h}$. The inherent viscosity increased with time initially, and reached 0.21 
$\mathrm{dL} \mathrm{g}^{-1}$ after $1 \mathrm{~h}$, but then did not change.

Similar to thermal reactions of the salts of 3-BMBA, the relative reactivity of the salts of 4-BMBA and of 4-BMPAA decreased in the order: $\mathrm{K}>\mathrm{Na} \gg \mathrm{Li}$, respectively. The X-ray diffraction patterns showed that the alkali salts of 4-BMBA and those of 4-BMPAA form crystalline salts, but the crystallinity of $\mathrm{Na}-4-\mathrm{BMBA}$ was much lower than those of $\mathrm{Li}-$ and $\mathrm{K}-4$-BMBA. The highest reactivity of the $\mathrm{K}$ salt was due to the effects of the potassium cation, which may lead to favorable molecular arrangement in the solid state for polycondensation, and higher crystallinity of the monomeric salt.

The relative reactivity of the corresponding salts of the carboxylic acids decreased in the order: 3 -BMBA $\fallingdotseq 4$ BMPAA $>4$-BMBA. In the solid-state thermal polycondensation of salts of 2-halogenopropanoic acid, the reaction may mainly proceed by a reaction mechanism such as a $S_{\mathrm{N}} 1$ reaction. ${ }^{2}$ It was considered that the reactions of the salts of BMBAs proceeded mainly in a reaction mechanism such as a $S_{\mathrm{N}} 1$ reaction due to the stability of a benzyl cation as an intermediate by the resonance effect of the phenyl group. The lower reactivity of salts of 4-BMBA was attributed to the lower stability of a benzyl cation because of an electronwithdrawing effect of a carboxyl group at 4-position. The electron-withdrawing effect of a carboxyl group at 3 -position influences the benzyl cation somewhat. The benzyl cation at 4-position, formed from 4-BMPAA, may be also affected somewhat by the electron-withdrawing effect of a carboxyl group because of a methylene group between an aromatic ring and carboxyl group. Thus, it was considered that the reactivity of the salts also depended upon the stability of the benzyl cation as an intermediate of the $S_{\mathrm{N}} 1$ reaction.

\section{CONCLUSIONS}

The thermal reactions of alkali salts of 3-BMBA, 4-BMBA, and 4-BMPAA in the solid state caused polycondensation, producing polyesters. Initially, the polycondensation proceeded rapidly, but then slowly. The relative reactivity of the salts decreased in the order: $\mathrm{K}>\mathrm{Na} \gg \mathrm{Li}$. The relative reactivity of the corresponding salts of the carboxylic acids decreased in the order: 3 -BMBA $\fallingdotseq 4$-BMPAA $>4$-BMBA. The reactivity of the salts depends upon the counter cation, crystallinity, and stability of the benzyl cation as an intermediate of the $S_{\mathrm{N}} 1$ reaction.

Acknowledgment. The authors thank Mr. Tadao Kuramochi of the Chemical Analysis Center, Chiba University, for carrying out the elemental analysis.

\section{REFERENCES}

1. Y. Takao, Y. Kasashima, M. Inoki, F. Akutsu, K. Naruchi, and Y. Yamaguchi, Polym. J., 27, 766 (1995).

2. F. Akutsu, M. Inoki, T. Morita, Y. Takao, K. Naruchi, and Y. Yamaguchi, Polym. J., 27, 1147 (1995).

3. G. G. Cameron, G. M. Buchan, and K. S. Law, Polymer, 22, 558 (1981).

4. A. G. Pinkus, R. Subramanyam, and R. Hariharan, J. Macromol. Sci., Pure Appl. Chem., A29, 1031 (1992).

5. Z. Zamorsky and R. Vesely, Chem. Prum., 8, 106 (1958) Chem. Abstr., 52, 15633f (1958).

6. A. G. Pinkus and R. Hariharan, J. Macromol. Sci., Rev. Macromol. Chem. Phys., C33, 259 (1993).

7. S. Owaki, K. Okawa, and K. Iohara, Jpn. Kokai Tokkyo Koho; 87-149911 (1987) [Chem. Abstr., 107, 177926k (1987)]

8. J. G. Cook, J. T. Dickson, A. R. Lowe, and J. R. Winfield, Br. Patent 604985 (1948) [Chem Abstr., 43, 1223g (1949)].

9. W. Sweeney, J. Appl. Polym. Sci., 7, 1983 (1963).

10. B. Ozgun and C. Tuzun, Commun. Fac. Sci. Univ. Ankara, Ser. B, Chim., 26, 55 (1980) [Chem. Abstr., 95, 81581b (1981)].

11. E. E. Paschke and S. A. Cerefice, U.S. Patent 4431798 (1984) [Chem. Abstr., 100, 192580s (1984)].

12. G. D. Brindell, L. D. Lillwitz, J. P. Wuskell, and A. P. Dunlop, Ind. Eng. Chem., Prod. Res. Dev., 15, 83 (1976)

13. S. A. Cerefice, E. K. Fields, K. A. Marchant Jr., and E. E. Paschke, U.S. Patent 4130719 (1978) [Chem. Abstr., 90, 138400v (1979)].

14. E. K. Fields, S. A. Cerefice, and E. E. Paschke, U.S. Patent 4182847 (1980) [Chem. Abstr., 93, 47450g (1980)]

15. C. S. Marvel and E. A. Kraiman, J. Org. Chem., 18, 707 (1953)

16. D. L. Tuleen and B. A. Hess, J. Chem. Educ., 48, 476 (1971)

17. E. S. Olson, J. Chem. Educ., 57, 157 (1980).

18. A. Singh, L. J. Andrews, and R. M. Keefer, J. Am. Chem. Soc., 84, 1179 (1962)

19. J. B. Shoesmith, A. C. Hetherington, and R. H. Slator, J. Chem. Soc., 125, 1312 (1924).

20. J. H. Gardner and C. A. Naylor, Jr., Org. Synth., Collect. Vol. II, 526 (1936).

21. L. Chauffe, L. J. Andrews, and R. M. Keefer, J. Org. Chem., 31, 3758 (1966)

22. H. Morawetz and I. D. Rubin, J. Polym. Sci., 57, 669 (1962).

23. J. B. Lando and H. Morawetz, J. Polym. Sci., C, Polym. Symp., 4, 789 (1963). 